\title{
As permanências dos desafios ambientais nos espaços urbanos
}

\author{
César Marques*
}

\author{
OJIMA, R.; MARANDOLA JR., E. Mudanças climáticas e as cidades: novos e antigos \\ debates na sustentabilidade urbana e social. São Paulo: Ed. Blucher, 2013. 272 p. \\ (Coleção População e Sustentabilidade).
}

O crescimento da população urbana e da importância das cidades na dinâmica social brasileira foi um dos fenômenos mais marcantes do país durante a segunda metade do século XX. São muitas as consequências desse novo padrão de uso do espaço, das quais as questões ambientais, principalmente no escopo das mudanças ambientais globais, têm recebido crescente atenção. Na discussão demográfica, duas décadas após o lançamento da obra seminal organizada por Martine (1993), os trabalhos da área de população e ambiente atualmente chegam com uma já consolidação do tema das cidades, convergindo para um debate população-urbanização-ambiente. Nessa perspectiva, as questões das ruralidades não são deixadas de lado, sendo analisadas as especificidades das diversas morfologias e relações do urbano no Brasil.

Nesse escopo, a obra Mudanças climáticas e as cidades: novos e antigos debates na busca da sustentabilidade urbana e social, organizada por Ricardo Ojima e Eduardo Marandola Jr., traz uma série de reflexões das principais dimensões do fazer científico e das práticas de políticas públicas que tocam na "agenda marrom", o campo de pesquisas ambientais que tem como eixo de análise as dinâmicas urbanas.

O livro está estruturado em três partes, que traduzem as principais questões e abordagens conceituais dessa chamada "agenda marrom": Política Urbana; Vulnerabilidade e Resiliência; e Adaptação e Mitigação. Como conceitos transversais e interdisciplinares, tal estruturação reflete o desafio de demógrafos e estudiosos de áreas afins, que, ao discutirem as interações entre população e ambiente, buscam uma série de disciplinas e abordagens que captem as várias dimensões desse fenômeno.

\footnotetext{
*Escola Nacional de Ciências Estatísticas (Ence), Instituto Brasileiro de Geografia e Estatística (IBGE), Rio de Janeiro-RJ, Brasil (cesar.m.silva@ibge.gov.br).
} 
Na primeira parte, Política Urbana, tem-se o debate sobre os mecanismos institucionais e as possibilidades de políticas que incorporem aspectos da mudança climática em seus desenhos. O primeiro capítulo, de Laura Bueno, trata da adaptação das cidades à mudança climática. A pesquisadora discute como os principais problemas da crise ambiental são profundamente relacionados às cidades, que não só serão impactadas pelas mudanças ambientais, locais e globais, como também causaram, ao menos parcialmente, tais problemas. São destacados o efeito estufa, as chuvas ácidas, a extinção de ambientes naturais, a destruição do ozônio atmosférico, a erosão e a perda de fontes de água doce, todos esses problemas relacionados à mudança climática, pois são reflexo da relação sociedade e natureza baseada no consumo excessivo de recursos naturais com consequente emissão e descarte de poluentes na própria natureza.

Nesse cenário, coloca-se que a diversidade das cidades, com relação a suas formas, tamanhos e demanda por recursos naturais, leva ao transbordamento das suas fronteiras físicas, o que implica a necessidade de políticas mais abrangentes. Contudo, nas cidades brasileiras, as políticas de adaptação ainda ocorrem de forma desarticulada, tanto interna como externamente. Dentro das cidades, as várias secretarias agem individualmente e, entre as cidades, não há uma abordagem conjunta.

Em termos temáticos, advoga-se que as políticas urbanas integrem as agendas marrom e verde, lidando com os problemas ambientais urbanos e a preservação da biodiversidade. Pensando na Região Metropolitana de Campinas como estudo de caso, a autora coloca que os impactos da periurbanização, com permissividade a mudanças no uso do solo e cobertura da terra, iriam exatamente na direção contrária dessa integração.

Desse modo, se os problemas socioambientais urbanos já não são equacionados, defende-se que as políticas relacionadas às mudanças climáticas não representem um novo imperativo, mas sejam capazes de acelerar a solução de demandas existentes, evitando o perigo de reiterar as injustiças ambientais. Diante do contexto de indeterminação e incerteza, é necessário assumir o princípio da precaução, ou seja, planejar a urbe considerando as alterações processuais das mudanças climáticas.

O segundo capítulo, escrito por Alisson Barbieri e Raquel Viana, aborda a interação entre planejamento urbano e mudanças climáticas a partir das experiências na gestão da Região Metropolitana de Belo Horizonte (RMBH). Para o embasamento da discussão, os autores ressaltam o papel do IPCC (Intergovernmental Panel on Climate Change) na criação de uma plataforma política para a discussão das mudanças climáticas, mas colocam que é necessário balancear a discussão e implantação, no contexto urbano, de medidas de adaptação (menos frequentes) em relação às medidas mais frequentes de mitigação.

No caso da RMBH é debatido o plano diretor de desenvolvimento integrado, cuja coordenação geral ficou a cargo do Centro de Planejamento e Desenvolvimento Regional - Cedeplar/UFMG. O plano foi construído a partir dos princípios da democracia, da participação e inclusão social, com uma proposta de elaboração participativa bottomup. Foram três ciclos de debates públicos, com discussão em três núcleos temáticos 
(desenvolvimento econômico, desenvolvimento social e desenvolvimento ambiental) e dez áreas transversais, cobrindo questões demográficas, ambientais, de cultura, educação, saúde, uso do solo, entre outras.

O resultado do projeto foi a proposição de um planejamento contínuo, baseado em quatro eixos integradores: acessibilidade, seguridade, sustentabilidade e urbanidade. De modo específico, cada um desses eixos gerou propostas específicas, mas que perpassam a questão das mudanças climáticas, formuladas segundo preocupações internalizadas pela própria população, inclusive.

Finalizando a primeira parte do livro, o capítulo de Marcelo Vargas explora o tema das águas urbanas, no contexto das mudanças climáticas, no que diz respeito tanto à vulnerabilidade como à mitigação, a partir de um estudo de caso na Região Metropolitana da Baixada Santista (RMBS). O estudo é focado na vulnerabilidade e adaptação da gestão dos recursos hídricos e saneamento em dois campos: hidrotécnico e hidropolítico. O primeiro envolve os aspectos técnicos, relacionados a abastecimento, esgotamento, drenagem e outros. Já o segundo engloba a questão de uma forma mais ampla, tratando das dimensões física (infraestrutura), gerencial (preparo de gestores) e social (falta de acesso e exclusão de determinados grupos ao saneamento básico).

Especificamente para a RMBS, o pesquisador nota que não há preocupação com a incorporação do tema das mudanças climáticas por diversos órgãos, municipais e regionais, assim como falta integração regional no enfrentamento da questão. Se, por um lado, há certa preocupação com temas correlatos às mudanças climáticas, como os eventos extremos, por outro, faltam políticas em relação às mudanças climáticas.

Na segunda parte do livro, Vulnerabilidade e Resiliência, são discutidas as possibilidades de abordagens conceituais utilizadas para as análises dos impactos e das possibilidades de resposta das cidades às mudanças climáticas.

O capítulo de Eduardo Marandola Jr. explora os desafios da escala em análises sobre vulnerabilidade e mudanças climáticas, problematizando essa questão de um ponto de vista epistemológico. $\mathrm{O}$ autor parte da constatação de que há um triplo desencaixe escalar: na ocorrência dos eventos, na gestão do território e entre os olhares disciplinares. Desse modo, se a vulnerabilidade é multidisciplinar, é, portanto, multiescalar. Para o pesquisador, a escala é um recorte epistemológico, que envolve o problema de hierarquia e de grandeza (dimensão), mas também incorpora noções de extensão, resolução, níveis, rede e relação, como discutido no já clássico artigo de Gibson, Ostrom e Ahn (2000). Assim, a escolha da escala é a escolha da visibilidade de um fenômeno em detrimento de outro, é um ajuste necessário para que o fenômeno estudado seja apreendido no seu próprio contexto. De modo sintético, o autor propõe que, para as escalas do clima, sejam realizadas abordagens sobre os ritmos do clima e, para as escalas de produção e gestão de riscos, sejam observadas as dinâmicas intraurbanas e sua respectiva articulação com a escala política. Por fim, é ressaltada a natureza trans e multiescalar da mudança ambiental, que envolve as cidades e as regiões, assim como suas vulnerabilidades. O maior desafio seria construir uma perspectiva em que 
as escalas sejam lentes, e não recortes, nas quais se possam observar as várias escalas, movendo-se nas direções por elas colocadas.

O capítulo de Sébastien Oliveau e Cristophe Guilmoto discorre acerca das oportunidades e desafios da integração do espaço nos estudos de população. A partir do grande aumento de informações espaciais, as técnicas e análises que levam em conta o espaço ampliaramse significativamente, com avanços da computação, desenvolvimento dos SIGs e revolução da distribuição dos produtos cartográficos. Isso permitiu um direcionamento a pesquisas espacializadas, com coleta de dados e representação da informação espacial, com posterior desenvolvimento de modelos explicitamente espaciais. Destacam-se a simulação do papel do espaço e a importância das abordagens multiagentes. Dadas as dificuldades em simular comportamentos por meio de experiências nas ciências sociais, há dificuldade em colocar as evidências ou causalidades, já que os modelos recaem nas correlações observadas. Assim, as abordagens multiagentes poderiam simular comportamentos e o papel do espaço sobre esses.

Já o trabalho de Francisco Mendonça, Marley Deschamps e Myriam del Veccio de Lima discute as interfaces entre mudanças climáticas, riscos e vulnerabilidade na cidade, especificamente na Região Metropolitana de Curitiba. Assumindo uma posição crítica em relação ao debate sobre as mudanças ambientais globais, os autores indicam a necessidade de se considerar a relação dos riscos com a intensificação de processos locais, tais como a urbanização. Ou seja, é necessário situar as mudanças climáticas no âmbito de todas as outras mudanças globais e de seus rebatimentos locais. A base do estudo é, nesse sentido, a crítica à ciência hegemônica, aos meios de comunicação de massa que criam um imaginário comum e à lógica da urbanização, que é refletida na segregação socioespacial.

Os dois argumentos centrais são relativos à lógica da percepção da população e à lógica da urbanização. Primeiramente, a percepção da população sobre o aumento dos desastres relacionados às mudanças climáticas é mediada pela mídia, que recorta os assuntos e molda opiniões. Influenciada pelo registro em tempo real dos riscos e desastres, haveria uma percepção de aparente intensificação de suas incidências, que não seria necessariamente real. Em segundo lugar, o debate da intensificação dos riscos e vulnerabilidades socioambientais deve ser contextualizado ao processo de urbanização. No Brasil, esse processo foi marcado pela criação insuficiente de infraestrutura, pela concentração da pobreza, por um caráter corporativo e com uma lógica de distribuição desigual dos danos ambientais.

No caso específico de Curitiba, os pesquisadores ressaltam a correlação entre áreas de alta vulnerabilidade social e a ocupação de áreas com risco ambiental, notando o agravamento da situação conforme aumenta a distância em relação ao centro. De igual modo, a dinâmica das inundações também se mostrou sensível quanto à urbanização, com aumento da primeira em função do espraiamento da mancha urbana. Em síntese, o estudo faz uma contraposição entre a dinâmica local e as mudanças climáticas globais, deslocando o foco dos problemas ambientais para a lógica da urbanização de alta segregação espacial, que gerou um contingente cada vez maior de pessoas expostas aos riscos de processos pluviais intensos. 
Na escala internacional, Lucí Nunes, Norma Valencio e Cláudia da Costa debatem os impactos das mudanças climáticas em países africanos, especialmente em relação aos fluxos populacionais. Sublinham-se os processos de urbanização precária do continente, sua instabilidade política e a xenofobia, que, associados às mudanças climáticas e aos desastres do presente, criam um cenário de inviabilização de reprodução social de uma série de populações. Nele, a desestruturação econômica, as características físicas do continente e o baixo grau de democracia contribuíram para a alta vulnerabilidade da população.

Não cedendo à tentação da generalização e não se perdendo nas especificidades, as pesquisadoras expõem uma série de casos, em termos qualitativos e quantitativos, problematizando a relação entre refugiados, deslocados ambientais e racismo, em que os deslocados são tratados como sujeitos supérfluos. Como exemplo, a própria Organização das Nações Unidas não está preparada para lidar com esse grupo, no sentido de combater esse universo de fragmentação e negação de direitos. Reitera-se assim um ambiente propício à difusão de desigualdades históricas, como as raciais, a da afirmação da superficialidade dos migrantes e do incremento das desigualdades de gênero.

No último capítulo da segunda parte, Tathiane Anazawa, Flávia Feitosa e Antônio Miguel Monteiro trazem avanços teóricos e metodológicos para as análises de vulnerabilidade, a partir da construção do Índice de Vulnerabilidade Socioecológica (IVSE). Para tanto, os autores seguem uma argumentação que tem se consolidado, na qual as cidades são investigadas enquanto sistemas socioecológicos (OSTROM, 2009). O termo vulnerabilidade é tomado como um conceito mediador (entre disciplinas), que pode ser representado por objetos mediadores, que são as operacionalizações do conceito. Nesse caso, o objeto mediador é o próprio IVSE, acompanhado de mapas de superfície e gráficos. Conceitualmente, há busca da conciliação entre os enfoques que tratam da vulnerabilidade nos aspectos territoriais, físicos e sociológicos.

Tomando o caso da cidade de São Sebastião, litoral norte de São Paulo, o estudo traz como produtos finais o IVSE e um painel de informações, decompondo os indicadores nas suas respectivas dimensões. Observa-se uma alta correlação espacial dos índices de vulnerabilidade, com células menos vulneráveis cercadas por outras também pouco vulneráveis, e as células de alta vulnerabilidade cercadas por células nas mesmas condições. Ademais, o debate proposto vai além da criação de um índice genérico e atenta para o perigo de conclusões que indiquem homogeneidade em locais heterogêneos, já que áreas com valores sintéticos semelhantes apresentaram perfis de ativos distintos.

A terceira e última parte, Adaptação e Mitigação, conta com dois capítulos debatendo a temática. No primeiro deles, Carlos Mello Garcias e Eduardo Gomes Pinheiro tratam da inserção do risco de desastres no escopo do planejamento urbano. Debatendo as questões sobrepostas ao plano diretor municipal, ao Estatuto das Cidades e aos Planos Diretores de Defesa Civil, os autores ressaltam a importância de planos de gestão de riscos e desastres como parte do enfrentamento das mudanças climáticas. Nesse escopo, os pesquisadores discutem o conceito de proteção e defesa civil para o país, mostrando como os termos, 
ligados a questões de ordem militar e de defesa, vêm sendo retrabalhados para que possam embasar uma postura mais ampla, pautada no termo proteção civil. Contudo, ainda existem claros desafios, com força residual da ideia de doutrina.

No âmbito das cidades, problematiza-se o mapeamento dos riscos, já que esses não interferem na promoção da segurança urbana em relação aos desastres e não trazem mudanças na configuração de poder que trata do uso do solo. Nesse sentido, a importância deveria recair sobre a interação entre os debates do planejamento urbano, dos desastres e da atuação da defesa e proteção civil, a partir de uma visão que englobe tanto as oportunidades como os perigos da política urbana, que pode reiterar ou combater novas vulnerabilidades.

No capítulo final, Ricardo Ojima explora os avanços dos estudos urbanos na compreensão das vulnerabilidades em cidades no contexto das mudanças climáticas. Para isso, o autor discute o papel atribuído às cidades nos cenários de mudanças climáticas e como as pesquisas ambientais e urbanas têm lidado com a questão das mudanças climáticas. Em relação às projeções climáticas, Ojima problematiza o fato de os modelos incluírem somente os totais populacionais, não estimando os diferenciais etários ou espaciais de distintas populações. Assim, considerar o incremento populacional urbano e rural seria importante, tal como incluir medidas relativas à pegada ecológica, que permitam uma compreensão mais detalhada e diferencial dos impactos populacionais no clima. De fato, para além das metodologias do IPCC, tais procedimentos já podem ser vistos em outras publicações, como em O`Neill et al. (2010).

Já para a questão da vulnerabilidade, denota-se sua dimensão contextual, relacionada aos fatores geográficos e sociais que vão além da suscetibilidade. Nesse caso ganham destaque as discussões sobre as abordagens transescalares e inter/transdisciplinares. Refletindo sobre a adaptação, o autor coloca que foram poucos os avanços sobre medidas na área. Para ele, refletir sobre tais medidas implica buscar a compreensão das vulnerabilidades de modo prospectivo. Nesse caso, admite-se que todas as cidades se adaptarão, com maior ou menor impacto, ampliando ou minimizando suas vulnerabilidades. Por fim, atenta-se para o fato de que a construção de medidas de sustentabilidade urbana vai além da incorporação de medidas clássicas de conservação ambiental, incluindo também questões de compreensão das vulnerabilidades e promoção da adaptação e resiliência.

Terminada a obra, é possível notar um panorama bastante amplo das principais questões que permeiam o campo de população, ambiente e urbanização, especialmente na discussão sobre mudanças climáticas. Nele, a dinâmica demográfica deve ser incorporada, mas dentro de um quadro mais amplo, que também considere as tensões políticas, sociais e disciplinares que conformam esse campo.

O livro traz avanços importantes para a área e mostra sua relativa consolidação. Entre os caminhos aqui apontados, destacam-se três questões: as demandas e possibilidades já existentes de análises espaciais; a discussão conceitual do trinômio mitigaçãovulnerabilidade-adaptação e sua apropriação pelos estudos de população e ambiente; e a demanda por um arcabouço mais amplo de olhares, tanto do ponto de vista disciplinar como no diálogo mais intenso com as políticas públicas e com os atores que as formulam. 
Por fim, é necessário ressaltar que tais esforços não são excludentes, mas sim sobrepostos. Análises que incluam essas três dimensões, entre outras, constituem uma tendência importante do campo. As pesquisas e discussões aqui sintetizadas mostram que tal caminho não só é possível, mas também um objetivo a ser perseguido.

\section{Referências}

GIBSON, C. C.; OSTROM, E.; AHN, T. K. The concept of scale and the human dimension of global change: a survey. Ecological Economics, v. 32, n. 2, 2000.

MARTINE, G. (Org.). População, meio ambiente e desenvolvimento: verdades e contradições. Campinas: Ed. da Unicamp, 1993.

O'NEILL, B.; DALTON, M.; FUCHS, R.; IIANG, L.; PACHAURI, S.; ZIGOVA, K. Global demographic trends and future carbon emissions. Proceedings of the National Academy of Sciences, v. 107, n. 41, 2010.

OSTROM, E. A general framework for analyzing sustainability of social-ecological systems. Science, v. 325, n. $5939,2009$.

\section{Sobre o autor}

César Marques é sociólogo, doutor em Demografia pela Universidade Estadual de Campinas. Pesquisador e professor do Mestrado em População, Território e Estatísticas Públicas, da Escola Nacional de Ciências Estatísticas - Ence/IBGE.

\section{Endereço para correspondência}

André Cavalcanti, 106, sala 502, Santa Teresa

20231-050 - Rio de Janeiro-RJ, Brasil 
